\title{
PENGARUH KEUNGGULAN KOMPETITIF DAN KUALITAS PELAYANAN TERHADAP KEPUASAN DAN LOYALITAS PENGUNJUNG OBJEK WISATA AIR "OWABONG" PURBALINGGA
}

\author{
Eru Ahmadia \\ Magister Manajemen Universitas Muhammadiyah Surakarta \\ Jl. A. Yani Pabelan Kartasura Surakarta 57102 \\ Email: eru.ahmadia@gmail.com
}

\begin{abstract}
This study aims to determine and analyze the effects of competitive advantage and service quality to customer satisfaction, and the subsequent impact on the loyalty of Owabong Water Park Purbalingga visitors. This research is a descriptive causal research, using survey method. The population of the research is Owabong Water Park visitors. This research usesa sample of 100 visitors. The sampling is done through convenience sampling technique. Data in this study are collected from questionnaires distributed to the samples, and other secondary data available. The data analysis is done using path analysis.Based on the analysis, the study concludes that: the competitive advantage and service quality have positive and significant effect on customer satisfaction either partially and simultaneously; customer satisfaction has a positive and significant effect on customer loyalty; competitive advantage and service quality do not have a direct effect on customer loyalty; and there are indirect effects of competitive advantage and service quality tocustomer loyalty through customer satisfaction.
\end{abstract}

Keywords: Loyalty, Satisfaction, competitive advantage, service quality.

\begin{abstract}
Abstrak
Tujuan penelitian ini adalah untuk mengetahui dan menganalisis pengaruh keunggulan kompetitif dan kualitas pelayanan terhadap kepuasan pengunjung serta dampak selanjutnya terhadap loyalitas pengunjung.Penelitian ini merupakan penelitian deskriptif kausal, dengan menggunakan metode survei.Populasi dalam penelitian ini adalah seluruh pengunjung Obyek Wisata Air "Owabong" di Kabupaten Purbalingga.Sampel yang digunakan dalam penelitian adalah sebanyak 100 orang responden.Penentuan sampel dilakukan dengan menggunakan teknik convenience sampling.Pengumpulan data dilakukan dengan menggunakan kuesioner dan dokumen. Teknik analisis data dilakukan dengan menggunakan analisis jalur (path analysis).Berdasarkan hasil analisis, penelitian menyimpulkan bahwa:Keunggulan kompetitif dan kualitas pelayanan berpengaruh positif dan signifikan terhadap kepuasan pengunjung baik secara parsial maupun secara simultan;Kepuasan pengunjungberpengaruh positif dan signifikan terhadap loyalitas pengunjung; Keunggulan kompetitif dan kualitas pelayanan tidak berpengaruh secara langsung terhadap loyalitas pengunjung;dan Ada pengaruh tidak langsung keunggulan kompetitif dan kualitas pelayanan terhadap loyalitas pengunjung melalui kepuasan pengunjung.
\end{abstract}

Kata kunci: Loyalitas, kepuasan, keunggulan kompetitif, kualitas pelayanan 


\section{Pendahuluan}

Salah satu tujuan wisata yang terkenal di Kabupaten Purbalingga adalah Obyek Wisata Air Owabong. Owabong merupakan Objek Wisata Air Bojongsari. Pada awalnya, objek wisata ini adalah sebuah pemandian umum (kolam renang), yang terletak di lokasi yang sama, desa Bojongsari. Kini, Owabong menjadi tujuan wisata terbesar di Jawa Tengah. Didukung oleh sumber mata air yang berlimpah dari Tuk Cidandang, Cipawon, dan Cikupel untuk menikmati kesegaran mata air pegunungan dengan wahana WaterBoom, Pantai Bebas Tsunami, sampai dengan Ember Tumpah. Selain wisata air, disediakan pula wahana seru lainnya seperti Gokart dan Terapi Ikan.

Obyek Wisata Air Owabong diresmikan secara Soft Opening oleh Bupati Purbalingga pada tanggal 1 Maret 2005 dan diresmikan kembali oleh Gubernur Jawa Tengah pada tanggal 18 Maret 2005 sebagai peresmian Grand Opening. Sejak diresmikan pada tahun 2005, jumlah pengunjung ke obyek wisata Owabong mengalami peningkatan dari tahun ke tahun.

Jumlah pengunjung mengalami penurunan pada tahun 2008 - 2011. Penurunan jumlah pengunjung tersebut tidak terlepas dari bermunculannya objek-objek wisata lain seperti Kamping Semawis di Semarang, Dream Land di Salatiga, Dedy Jaya Water Boom di Tegal, Surya Yudha Park di Banjarnegara, Sabda Alam di Garut dan masih banyak lagi obyek-obyek wisata sejenis yang berdiri di beberapa daerah, dengan kemunculan obyek wisata tersebut sedikit banyak ikut berkontribusi terhadap penurunan jumlah pengunjung di Owabong.

Munculnya objek-objek wisata baru di wilayah sekitar yang berdekatan dengan berbagai daya tarik yang ditawarkan, mau tidak mau harus menjadi pertimbangan bagi operator objek wisata Owabong untuk terus meningkatkan daya saing atau daya tarik yang dimilikinya agar tidak semakin ditinggalkan oleh para pengunjungnya. Sejak adanya peningkatan fasilitas, yang dilakukan pada tahun 2011, jumlah pengunjung mengalami peningkatan. Hal ini berkaitan dengan meningkatnya daya tarik tujuan wisata seiring dengan pengembangan yang dilakukan.

Daya tarik suatu objek wisata itu sendiri menurut Getz (dalam Fyall, 2003) mencakup tujuh elemen yang meliputi: (1) infrastruktur; (2) akomodasi; (3) transportasi; (4) atraksi; (5) catering; (6) pedagang pengecer; dan (7) sarana rekreasi atau hiburan. Sedangkan menurut Fyall, et al (2003), daya tarik objek wisata diklasifikasikan ke dalam 6 elemen, yaitu: (1) atraksi (attractions); (2) keterjangkauan (accessibility); (3) akomodasi (amenities); (4)paket yang tersedia (available packages); (5) aktivitas yang ada (activities); dan (6) layanan penunjang yang sering digunakan oleh wisatawan seperti bank, rumah sakit, telekomunikasi, dan lain-lain (ancillary services). Elemen-elemen tersebut merupakan faktor-faktor yang menjadi keunggulan kompetitif (competitive advantage) bagi suatu objek wisata.

Kotler (2006) dan Buhalis (2000) menyatakan bahwa tujuan wisata, sebagai suatu produk pariwisata, merupakan suatu entitas yang paling sulit dikelola dan dipasarkan. Hal ini dikarenakan adanya kompleksitas hubungan yang ada di antara para pemangku kepentingan lokal.

Atas dasar hal itu, Buhalis (2010) lebih lanjut menjelaskan bahwa pengembangan dan tujuan-tujuan implementasi stratejik pada objek wisata antara lain meliputi: 1) meningkatkan kesejahteraan masyarakat sekitar objek wisata tersebut dalam jangka panjang; 2) menarik kunjungan wisatawan dengan memaksimalkan kepuasan mereka; 3) memaksimalkan profitabilitas perusahaanperusahaan di sekitar objek wisata tersebut dan memaksimalkan efek-efek multipliernya; serta 4) mengoptimalkan dampakdampak pariwisata tersebut dengan cara menyeimbangkan antara manfaat-manfaat ekonomis yang dihasilkan dengan biayabiaya sosial budaya dan lingkungan yang ditimbulkannya. 


\section{Tinjauan Pustaka}

Kotler (2006) menyebutkan bahwa persaingan global dan konsentrasi objek wisata dapat menimbulkan berbagai tantangan dan permasalahan dalam hal penciptaan loyalitas pelanggan dan keunggulan kompetitifdalam pasar produk pariwisata. Hal ini dikemukakan oleh Kotler sebagai berikut:

\section{"Global competitiveness and tourism concentration create numerous challenges and problems in the creation of consumer loyalty and sustainable competitive advantage in the tourism product market".}

Menurut pendapat Kotler tersebut tergambar bahwa dalam pemasaran produk pariwisata, keunggulan kompetitif berpengaruh terhadap loyalitas pelanggan, terutama dalam persaingan global di masa sekarang ini.Hal ini menuntut adanya peningkatan keunggulan kompetitif pada suatu objek pariwisata agar mampu bertahan dalam persaingan global yang semakin ketat, sehingga kepuasan konsumen meningkat yang pada gilirannya dapat meningkatkan loyalitas pelanggan.

Keunggulan kompetitif yang mencakup enam aspek sebagaimana dijelaskan oleh Fyall, et al. (2003), menjadi daya tarik suatu objek wisata guna menarik kedatangan pengunjung. Selain keunggulan kompetitif, faktor lain yang dipandang dapat meningkatkan kepuasan pelanggan adalah kualitas pelayanan.

Kualitas pelayanan dalam produk jasa, menurut Zeithamal, et al. (2002) terdiri dari 5 aspek yang meliputi : bukti langsung (tangibles), kendala (reliability), daya tanggap (responsiveness), Jaminan (assurance), dan kepedulian (emphaty). Kelima aspek tersebut apabila dikelola dengan baik akan dapat meningkatkan kepuasan pelanggan, yang pada gilirannya akan dapat meningkatkan loyalitas pelanggan. Hal ini didukung oleh temuan penelitian yang dilakukan oleh Donnelly (2009) yang menyimpulkan bahwa kualitas, nilai-nilai, dan kepuasan pelanggan merupakan faktor-faktor penentu utama loyaltias pelanggan objek pariwisata.

Dikaitkan dengan objek wisata, maka kepuasan pengunjung dapat diartikan diukur sebagai "the total of comments by the tourists on each destination's quality" (Prayag dalam Coban, 2012). Sedangkan menurut Baker dan Crompton (dalam Coban, 2012), kepuasan pelanggan dalam studi pariwisata didefinisikan sebagai keadaan emosi pengunjung setelah mereka melakukan kunjungan wisata. Pengukuran kepuasan jenis ini dapat dianggap sebagai penilaian terhadapkualitas kinerja tujuan wisata seperti bagaimana wisatawan dilayani saat di tempat wisata.

Mengacu pada pendapat Shemwell, Yavas and Bilgin (1998: p. 165) justifikasi dimensi dari consumer satisfaction dapat diturunkan dari dimensi service quality. Lima dimensi penilaian kepuasan antara lain: kehandalan (reliability), respon (responsiveness), keyakinan (assurance), empati (emphaty), berwujud (tangible).

Beberapapenelitianmenghasilkantemuan bahwa kualitas jasa dan citra objek wisata menjadi penentu kepuasan pengunjung. Chen \& Tsai, 2006; Coban, 2012; Yeung \& Leung, 2010; Yoon, 2005; Suki, 2012; Haghkhah et al. 2012]. Penelitian yang dilakukan Fyall et al., (2003) menghasilkan kesimpulan bahwa faktor keunggulan kompetitif suatu objek wisata menjadi salah satu penentu kepuasan pelanggan.

Tjiptono (2005: 2009) menyebutkan bahwa salah satu faktor yang menentukan kepuasan pelanggan adalah kualitas jasa (service quality). Berdasarkan pendapatpendapat tersebut di atas, maka selanjutnya dapat disimpulkan bahwa faktor-faktor yang mempengaruhi kepuasan pengunjung antara lain meliputi: 1) kualitas jasa; dan 2) keunggulan kompetitif suatu objek wisata.

Berdasarkan hal-hal diatas maka dapat ditarik suatu kesimpulan bahwa kepuasan dapat dilihat dari beberapa indikator, yaitu: (1) kepuasan terhadap kemampuan untuk melaksanakan jasa yang dijanjikan, (2) kepuasan terhadap kemauan membantu 
pelanggan, (3) kepuasan terhadap pengetahuan dan kesopanan, (4) kepuasan terhadap kepedulian pada pelanggan, dan (5) kepuasan terhadap penampilan fasilitas fisik. Cronin and Taylor (dalam Coban, 2012) dalam penelitiannya berhasil membuktikan bahwa kepuasan pelanggan ditentukan oleh penilaian pelanggan terhadap kualitas pelayanan yang diberikan.

Penelitian yang dilakukan oleh Suki \& Norazah (2012) mengkaji pengaruh aspekaspek assurance, reliability, responsiveness, tangible, dan empathy terhadap kepuasan pengunjung. Penelitian dilakukan dengan menggunakan metode survai yang dilakukan terhadap 230 responden pengunjung hotel di Wilayah Teritorial Labuan, Malaysia. Analisis data dilakukan dengan menggunakan analisis regresi linier berganda. Hasil penelitian menyimpulkan bahwa aspek-aspek assurance, reliability, responsiveness, tangible, dan empathy berpengaruh signifikan terhadap kepuasan pengunjung. Empathy merupakan aspek yang berpengaruh dominan terhadap kepuasan pengunjung.

Penelitian yang dilakukan oleh Haghkhah, Nosratpour, Ibrahimpour, dan Hamid (2011) meneliti pengaruh kualitas pelayanan jasa pariwisata terhadap kepuasan pengunjung serta dampaknya terhadap loyalitas pengunjung. Metode yang digunakan merupakan meta analisis terhadap hasil-hasil penelitian sebelumnya Sehingga menghasilkan pemodelan matematis and kuantitatif. Hasil penelitian menyimpulkan bahwa kualitas pelayanan mempengaruhi kepuasan pengunjung. Adanya kepuasan pengunjung berdampak pada adanya keinginan untuk mengunjungi objek wisata tersebut.

Penelitian yang dilakukan oleh Yeung \& Leung (2010) mengkaji hubungan antara kualitas jasa, nilai, kepuasan pengunjung, dan loyalitas pengunjung. Penelitian menggunakan sampel sebanyak 232 responden pengunjung kapal wisata di Hong Kong.Analisis data dilakukan dengan menggunakan EFA, CFA dan SEM. Hasil penelitian menyimpulkan bahwa kualitas jasa mempengaruhi nilai kualitas yang diperoleh pelanggan, kepuasan dan loyalitas secara langsung. Nilai kualitas yang diperoleh dan kepuasan tidak berpengaruh langsung terhadap loyalitas.

Penelitian yang dilakukan oleh Donnelly (2009) menganalisis hubungan antara keunggulan kompetitif dan kualitas pelayanan dengan loyalitas pengunjung objek wisata baik secara langsung maupun secara tidak langsung melalui persepsi atas kualitas yang diterima pengunjung.Penelitian menggunakan tiga desain penelitian, yaitu exploratory research, deskriptif, dan kausalitas. Hasil penelitian menyimpulkan bahwa keunggulan kompetitif dan kualitas pelayanan berkorelasi signifikan dengan loyalitas pengunjung objek wisata baik secara langsung maupun secara tidak langsung melalui persepsi atas kualitas yang diterima pengunjung.

Penelitian yang dilakukan oleh Cerovic \& Batic (2008) mendeskripsikan unsurunsur kondisional strategi yang dilakukan perusahaan jasa pariwisata dan pengelola objek tujuan wisata untuk menempatkan positioning pasar mereka. Metode yang digunakan adalah studi pustaka. analisis yang digunakan adalah analisis SWOT untuk menetapkan strategi posisioning pasar. Hasil penelitian menyimpulkan bahwa faktor-faktor yang berkaitan dengan keunggulan kompetitif terdiri dari dua jenis, yaitu faktor dasar yang berkaitan dengan sumber daya objek wisata dan atraksi,yang meliputi pengetahuan dan kemampuan spesialis, teknologi baru, struktur komunikasi dan Infra struktur pasar.

PenelitianyangdilakukanolehDmitrovic', Cvelbar, Kolar, Brenc `ic ${ }^{`}$, Ograjens`ek dan Zabkar (2009) mengkonseptualisasikan suatu model kepuasan wisatawan di tingkat tujuan wisata yang dapat digunakan sebagai dasar untuk mendesain instrumen pengukuran. Model konseptual dikembangkan berdasarkan basis penelitian teoretis dan empiris di bidang pemasaran dan pariwisata. Hasil penelitian menyimpulkan bahwa model yang terbentuk mencakup delapan konstruk laten, dengan kepuasan wisatwan sebagai pusatnya. Analisis 
terhadap anteseden (kualitas, citra, nilai, dan biaya serya resiko) kepuasan pelanggan memberikan petunjuk kepada proses yang mendasari penciptaan kepuasan, sedangkan konstruk-konstruk hasil mengindikasikan adanya konsequensi ketidakpuasan.

Penelitian yang dilakukan oleh Machiori \& Fatoki (2011) mengkaji tentang kepuasan pelanggan di empat toko ritel besar di King William's Town, Afrika Selatan. Kepuasan pelanggan dan loyalitas merupakan faktor-faktor yang mempengaruhi kinerja perusahaan. Data dikumpulkan melalui kuesioner swakelola.Analisis data dilakukan dengan menggunakan statistik deskriptif, uji-T, ANOVA dan Chi kuadrat. Hasil penelitian menyimpulkan bahwa secara keseluruhan, para pelanggan merasa puas dan loyal terhadap keempat toko ritel tersebut. Hasil menunjukkan bahwa salah satu hal yang menjadikan pelanggan tidak puas adalah waktu antre.

Loyalitas pengunjung pada industri kepariwisataan sangatlah penting agar tidak terjadi dampak penurunan jumlah pengunjung, sebagaimana terjadi selama periode tahun 2009 - 2011. Apalagi dengan semakin banyaknya objek wisata baru yang bermunculan di kawasan yang relatif berdekatan dengan objek wisata tersebut. Salah satu cara yang dapat dilakukan adalah dengan melakukan riset pemasaran untuk mengetahui faktorfaktor yang dapat meningkatkan loyalitas pengunjung

Mengacu pada latar belakang permasalahan tersebut di atas, penelitian ini bertujuan untuk mengetahui dan menganalisis pengaruh keunggulan kompetitif dan kualitas pelayanan terhadap kepuasan pengunjung serta dampak selanjutnya terhadap loyalitas pengunjung.

\section{Metode Penelitian}

Penelitian ini menggunakan desain Kausal. Studi Kausal merupakan studi dimana peneliti ingin menemukan penyebab dari satu atau lebih masalah.
Metode penelitian yang digunakan dalam penelitian adalah metode survei. Metode survei merupakan metode penelitian yang menggunakan kuesioner sebagai alat pokok dalam mengumpulkan data dan informasi dari responden (Singarimbun dan Effendi, 2000). Menurut Malhotra \& Birks (2012: 108) survei adalah cara mengumpulkan data yang melibatkan wawancara dengan sejumlah besar responden dengan menggunakan kuesioner yang sudah disusun sebelumnya. Survei oleh Malhotra dan Birks dikatakan "involve interviews with a large number of respondents using a pre-designed questionnaire" (Malhotra \& Birks, 2012: 108).

Populasi dalam penelitian ini adalah seluruh pengunjung Obyek Wisata Air OWABONG di Kabupaten Purbalingga. Jumlah sampel ditetapkan sejumlah 100 orang. Hal ini sesuai dengan pendapat Roscoe (1975) sebagaimana dikutip oleh Sekaran (2006: 295) yang memberikan acuan dalam menentukan ukuran sampel.

Sampel penelitian ditentukan dengan menggunakan metode convenience sampling, yaitu metode pengambilan sampel yang mudah ditemui (Sugiyono, 2009). Hal ini dilakukan dengan menemui pengunjung satu per satu dan meminta pendapat mereka tentang keunggulan kompetitif, kualitas pelayanan, kepuasan pengunjung dan loyalitas terhadap objek wisata tersebut sehingga dapat diperoleh responden sebanyak 100 orang pengunjung.

Teknik analisis data yang digunakan dalam penelitian ini adalah analisis jalur (path analysis).Adapun model yang digunakan sebagai alat untuk pengujian hipotesis adalah model analisis jalur dengan menggunakan dua jalur (Sarwono, 2007: 15).Model umum diagram jalur dengan dua jalur terdiri dari dua model substruktur. Model tersebut menempatkan $X_{1}$ dan $X_{2}$ sebagai variabel eksogen dan $Y_{1}$ serta $Y_{2}$ sebagai variabel endogen.

Adapun persamaan struktural yang terbentuk berdasarkan variabel-variabel eksogen dan endogen. Persamaan struktur 
1 menggunakan skema korelasi $X_{1}$ dan $\mathrm{X}_{2}$ terhadap $\mathrm{Y}_{1}$. Persamaan struktur 2 menggunakan skema korelasi $X_{1}$ dan $X_{2}$, dan $\mathrm{Y}_{1}$ terhadap $\mathrm{Y}_{2}$.

\section{Penelitian dan Pembahasan}

Hipotesis yang menyatakan bahwa "keunggulan kompetitif dan kualitas pelayanan berpengaruh terhadap kepuasan pengunjung di objek wisata air Owabong, baik secara parsial maupun secara simultan" terbukti kebenarannya. Hal ini ditunjukkan dengan hasil analisis uji ketepatan model maupun uji ketepatan parameter penduga di mana diperoleh hasil uji $F$ dan uji $t$ yang signifikan secara statistik.

Hasil uji ketepatan model untuk menguji pengaruh variabel bebas terhadap variabel terikat secara bersama-sama diperoleh harga $\mathrm{F}$ sebesar 80.702dengan signifikansi $\square=0.000$. Berdasarkan hasil tersebut maka $\mathrm{H}_{0}$ ditolak dan $\mathrm{H}_{\mathrm{a}}$ diterima. Hal ini dapat diartikan bahwa ada kontribusi yang signifikan dari keunggulan kompetitif $\left(\mathrm{X}_{1}\right)$ dan kualitas pelayanan $\left(\mathrm{X}_{2}\right)$ secara bersama-sama terhadap kepuasan pengunjung $\left(\mathrm{Y}_{1}\right)$.

Besarnya pengaruh keunggulan kompetitif $\left(\mathrm{X}_{1}\right)$ dan kualitas pelayanan $\left(\mathrm{X}_{2}\right)$ secara bersama-sama terhadap kepuasan pengunjung $\left(\mathrm{Y}_{1}\right)$ ditunjukkan dengan nilai koefisien determinasi sebesar 0.625. Hal ini diartikan bahwa pengaruhkeunggulan kompetitif $\left(\mathrm{X}_{1}\right)$ dan kualitas pelayanan $\left(\mathrm{X}_{2}\right)$ secara bersama-sama menentukan variabilitas kepuasan pengunjung $\left(\mathrm{Y}_{1}\right)$ sebesar $62.50 \%$. Sisanya sebesar $37.50 \%$ ditentukan oleh variabel lain di luar model ini.

Hasil analisis uji ketepatan parameter penduga (estimasi) untuk mengetahui pengaruh keunggulan kompetitif $\left(\mathrm{X}_{1}\right)$ dan kualitas pelayanan $\left(\mathrm{X}_{2}\right)$ secara parsial terhadap kepuasan pengunjung $\left(\mathrm{Y}_{1}\right)$ menunjukkan nilai $\mathrm{t}$ yang signifikan secara statistik. Atas dasar hal tersebut,dapat disimpulkan bahwa keunggulan kompetitif $\left(\mathrm{X}_{1}\right)$ dan kualitas pelayanan $\left(\mathrm{X}_{2}\right)$ secara parsial berpengaruh signifikan terhadap kepuasan pengunjung $\left(\mathrm{Y}_{1}\right)$.
Temuan tersebut mendukung hasil penelitian yang dilakukan oleh Stankovic dan Dukic (2009) yang menyimpulkan bahwa keunggulan kompetitif suatu tujuan pariwisata sangat tergantung pada kemampuan objek tersebut dalam membangun citra. Keunggulan kompetitif tersebut selanjutnya akan mempengaruhi kepuasan pengunjung objek tersebut.

Temuan bahwa keunggulan kompetitif dan kualitas pelayanan berpengaruh terhadap kepuasan pengunjung di objek wisata air Owabong, baik secara parsial maupun secara simultan juga mendukung hasil penelitian yang dilakukan oleh Dimitrovic et al. (2008). Hasil penelitian menyimpulkan bahwa keunggulan kompetitif objek wisata berpengaruh positif dan signifikan terhadap kepuasan pengunjung; dan kualitas pelayanan yang ada di tujuan wisata berpengaruh positif terhadap kepuasan pengunjung.

Hipotesis yang menyatakan bahwa "kepuasan pengunjung berpengaruh signifikan terhadap loyalitas pengunjung di objek wisata air Owabong" terbukti kebenarannya. Hal ini ditunjukkan dengan hasil analisis uji parsial di mana diperoleh nilai t statistik sebesar 3.991, dengan signifikansi p sebesar 0.000.Mengingat nilai signifikansi $\mathrm{p}$ kurang dari 0.05 , maka $\mathrm{H}_{0}$ ditolak dan Ha diterima. Dengan demikian disimpulkan bahwa kepuasan pengunjung $\left(\mathrm{Y}_{1}\right)$ secara parsial berpengaruh signifikan terhadap loyalitas pengunjung $\left(\mathrm{Y}_{2}\right)$.

Temuan tersebut mendukung hasil penelitian yang dilakukan oleh Machirori dan Fatoki (2011) yang mengkaji tentang pengaruh kepuasan pelanggan terhadap loyalitas pelanggan pada toko-toko ritel besar di Afrika Selatan. Hasil penelitian menunjukkan bahwa kepuasan pelanggan berpengaruh signifikan terhadap loyalitas pelanggan.

Hipotesis yang menyatakan bahwa "keunggulan kompetitif dan kualitas pelayanan berpengaruh signifikan terhadap loyalitas pengunjung di objek wisata air Owabong" tidak terbukti kebenarannya. Hal ini ditunjukkan dengan rendahnya pengaruh langsung yang diberikan oleh keunggulan 
kompetitif dan kualitas pelayanan terhadap loyalitas pengunjung.

Hasil analisis menunjukkan bahwa pengaruh langsung (direct effect) yang diberikan oleh keunggulan kompetitif dan kualitas pelayanan terhadap loyalitas pengunjung adalah sangat rendah, yaitu 0.014 untuk keunggulan kompetitif dan 0.037 untuk kualitas pelayanan.Hasil analisis uji regresi pada persamaan sub-struktur 2 juga membuktikan bahwa pengaruh yang tidak signifikan diberikan oleh varabel keunggulan kompetitif dan kualitas pelayanan terhadap loyalitas pengunjung. Hal tersebut ditunjukkan dengan hasil uji $t$ yang tidak signifikan secara statistik, yaitu dengan $t$ sebesar sebesar 0.121 dengan signifikansi $p$ sebesar 0.904 untuk keunggulan kompetitif, dan nilai t sebesar 0.300 dengan signifikansi p sebesar 0.765 untuk kualitas pelayanan.

Temuan ini sejalan dengan temuan penelitian yang dilakukan oleh Haghkhah, Nosratpour, Ibrahimpour, dan Hamid (2011) yang mengkaji tentang pengaruh kualitas pelayanan jasa pariwisata terhadap kepuasan pengunjung serta dampaknya terhadap loyalitas pengunjung. Adanya kepuasan pengunjung berdampak pada adanya keinginan untuk mengunjungi objek wisata tersebut. Berdasarkan temuan penelitian, dapat diketahui bahwa kualitas pelayanan berpengaruh terhadap kepuasan konsumen. Kemudian dari kepuasan konsumen tersebut pada gilirannya akan mempengaruhi loyalitas konsumen.

Hipotesis yang menyatakan bahwa "keunggulan kompetitif dan kualitas pelayanan berpengaruh tidk langsung terhadap loyalitas pengunjung di objek wisata air Owabong melalui kepuasan pengunjung" terbukti kebenarannya. Hal ini ditunjukkan dengan besarnya pengaruh tidak langsung yang diberikan kedua variabel tersebut terhadap loyalitas pengunjung melalui kepuasan pengunjung cukup besar.

Hasil analisis penghitungan pengaruh tidak langsung (indirect effect) untuk variabel keunggulan kompetitif terhadap loyalitas pengunjung melalui kepuasan pengunjung diperoleh nilai korelasi sebesar 0.219 yang termasuk kategori agak rendah. Adapun penghitungan pengaruh total variabel keunggulan kompetitif terhadap loyalitas pengunjung melalui kepuasan pengunjung diperoleh nilai korelasi sebesar 0.947 yang termasuk korelasi sangat kuat.

Hasil analisis penghitungan pengaruh tidak langsung (indirect effect) untuk variabel kualitas pelayanan terhadap loyalitas pengunjung melalui kepuasan pengunjung diperoleh nilai korelasi sebesar 0.262 yang termasuk kategori agak rendah. Adapun penghitungan pengaruh total variabel kualitas pelayanan terhadap loyalitas pengunjung melalui kepuasan pengunjung diperoleh nilai korelasi sebesar 1.025 yang termasuk korelasi sangat kuat.

Temuan tersebut didukung dengan hasil penelitian yang dilakukan oleh Haghkhah, et al. (2011) yang menyimpulkan bahwa kualitas pelayanan mempengaruhi kepuasan pengunjung. Adanya kepuasan pengunjung berdampak pada adanya keinginan untuk mengunjungi objek wisata tersebut. Temuan tersebut juga didukung hasil penelitian yang dilakukan oleh Fyall (2003) yang menyimpulkan bahwa Keunggulan kompetitif suatu objek wisata yang meliputi enam komponen sebagaimana dan kualitas pelayanan akan berpengaruh terhadap kepuasan pengunjung. Adanya kepuasan yang diperoleh pengunjung terhadap suatu objek wisata akan mampu mendorong adanya keinginan untuk mengunjungi kembali objek wisata tersebutungdan kualitas pelayanan akan berpengaruh terhadap kepuasan pengunjung. Adanya kepuasan yang diperoleh pengunjung terhadap suatu objek wisata akan mampu mendorong adanya keinginan untuk mengunjungi kembali objek wisata tersebut.

Hasil penelitian bahwa keunggulan kompetitif dan kualitas pelayanan berpengaruh tidak langsung terhadap loyalitas pengunjung melalui kepuasan pengunjung juga dikuatkan dengan hasil 
penelitian Yeung dan Leung (2010) dengan judul "Relationships among Service Quality, Value, Customer Satisfaction and Loyalty in a Hong Kong Harbour Cruise Company". Penelitian ini mengkaji tentang pengaruh kualitas pelayanan terhadap kepuasan pelanggan, dan pengaruh kepuasan pelanggan terhadap loyalitas pelanggan. Hasil penelitian menunjukkan bahwa kualitas pelayanan berpengaruh terhadap kepuasan pelanggan, dan kualitas pelayanan berpengaruh terhadap loyalitas pelanggan secara tidak langsung melalui kepuasan yang diperoleh pelanggan.

\section{Penutup}

Keunggulan kompetitif dan kualitas pelayanan berpengaruh positif dan signifikan terhadap kepuasan pengunjung baik secara parsial maupun secara simultan.

Kepuasan pengunjung berpengaruh positif dan signifikan terhadap loyalitas pengunjung. Keunggulan kompetitif dan kualitas pelayanan tidak berpengaruh secara langsung. Hal ini ditunjukkan dengan rendahnya pengaruh langsung yang diberikan oleh keunggulan kompetitif dan kualitas pelayanan terhadap loyalitas pengunjung.
Ada pengaruh tidak langsung keunggulan kompetitif dan kualitas pelayanan terhadap loyalitas pengunjung melalui kepuasan pengunjung. Hal ini ditunjukkan dengan besarnya koefisian pengaruh tidak langsung dan pengaruh total yang diberikan kedua variabel terhadap loyalitas pengunjung.

Berdasarkan kesimpulan hasil penelitian, selanjutnya dapat dikemukakan implikasi hasil penelitian baik secara praktis maupun secara teoretis. Implikasi tersebut adalah sebagai berikut: 1) Semakin tinggi persepsi konsumen terhadap keunggulan kompetitif suatu produk atau jasa maka akan semakin tinggi kepuasan konsumen terhadap produk atau jasa yang diberikan. Hal tersebut pada gilirannya akan berdampak pada meningkatnya loyalitas konsumen terhadap produk atau jasa tersebut; 2) Semakin tinggi persepsi konsumen terhadap kualitas pelayanan yang diberikan maka akan semakin tinggi kepuasan konsumen terhadap jasa yang diberikan. Hal tersebut pada gilirannya akan berdampak pada meningkatnya loyalitas konsumen terhadap jasa tersebut; dan 3) Peningkatan loyalitas pelanggan dapat dilakukan dengan memperhatikan aspekaspek yang menjadi kepuasan pelanggan.

\section{Daftar Pustaka}

Bharadwaj, Sundar G, P.R.Varadarajan, \& Fahly, Jihn. 1993. Sustainable Competitive Advantage in Service Industries: A Conceptual Model and Research Propositions. Journal of Marketing. Vol.57,Oktober,p.83-99

Birdsall, Ian A, 2004 It Seemed Like a Good Idea at the Time: The Forces Affecting Implementation of Strategies for an Information Technology Project In the Department of Defense

Buhalis, D. 2000. "Marketing the Competitive Destination of the Future".Journal of Tourism Management Vol. 21, 2000, 97-116.

Cerovic, Slobodan and Saldjana Batic (2008) "Competitiveness and Positioning in Tourism" Journal of Economics and Organization Vol. 5, No 2, 2008, pp. 133 - 14.

Chang, Tung-Zong dan Su-Jane Chen. 1998. arket Orientation, Service Quality and Business Perfomance: a Conceptual Model and Empirical Evidence. Journal of Service Marketing. Vol.12, No.4

Chen JS, Gursoy D (2001) An investigation of tourists' destination loyalty and preferences. Int J Contemp Hospitality Manage 13(2):79-85 
Chen, Ching Fu, and Tsai Dung Chun (2007) "How destination image and evaluative factors affect behavioral intentions?" Journal of Tourism Management 28 (2007) 1115-1122.

Coban, Suzan. 2012, The effects of the image of destination on tourist satisfaction and loyality, the case of copadia.

Dmitrovic', Tanja, Ljubica Kneževic' Cvelbar, Tomaz` Kolar, Maja Makovec Brenc`ic`, Irena Ograjens `ek dan Vesna Zabkar (2009) "Conceptualizing tourist satisfac-tion at the Destination level" International Journal of Culture, Tourism and Hospitality Research Vol. 3 NO. 2 2009, pp. 116-12.

Donnelly, Martina. 2009."Building Customer Loyalty: A Customer Experience Based Approach in a Tourism Context". Thesis, submitted in fulfillment of the requirement for a Master Degree in Bussiness Study, Waterford Institute of Technology.

Fyall, A; Callod, C; Edwards, B. 2003. "Relationship Marketing: The Challenge for Destinations" Annals of Tourism Research, Vol. 30, No. 3, 2003, 644-659.

Getz, D. 1991. The impacts of mega events on tourism: Strategies for destinations. In Andersson, T. D., C. Persson, B. Sahlberg, \& L. Strom, (Ed.), The Impact of Mega Events. (pp.5-32). Ostersund, Sweden: European Tourism Research Institute.

Griffin, Jill. 2005. Customer Loyalty, Menumbuhkan dan Mempertahankan Kesetiaan Pelanggan. Erlangga. Jakarta

Haghkhah,Azam., Mehdi Nosratpour, Alireza Ibrahimpour, dan Abubakar Abd. Hamid (2011) "The Impact of Service Quality on Tourism Industry" $2^{\text {nd }}$ International Conference on Business and Economic Research (2 ${ }^{\text {nd }}$ ICBER 2011), pp: 1834-1854.

Jirawat, Anuwichanont dan Sirivan Serirat 2009.“Tourists'Loyalty towards Sustainable Night Tourism: A Case Study of Pattaya, Thailand".

Kotler, P; Bowen, T.J; Makens, C.J., Marketing for Hospitality and Tourism, Pearson Education, Inc., Upper Saddle River, New Jersey, 2006

Kotler, Philip. 2005. Manajamen Pemasaran, Jilid 1 dan 2. PT. Indeks. Jakarta.

Machiori, Tafadzwa, and Olawale Fatoki (2011) “An empirical investigation into the extent of customer satisfaction and customer loyalty at big retail stores in King William's Town, South Africa" African Journal of Business Management Vol. 5(17), pp. 7665-7673, 4 September, 2011.

Malhotra, Naresh K., and David F. Birks. 2012. Marketing Research: An Applied Approach $3^{r d}$ European Edition. Harlow, England: Prentice-Hall.

Mowen, John C, 1995, Consumer behavior, Prentice Hall, Inc, Englewood Cliffs, New Jersey, International Edition

Sarwono, Jonathan. 2007. Analisis Jalur untuk Riset Bisnis dengan SPSS. Yogyakarta: Andi Offsett.

Sekaran, Uma. 2002. Research Methods for Business: A Skill Building Approach, Third Edition. New York: John Wiley \& Sons, Inc.

Singarimbun, Masri dan Effendi, Sofian. 2000. Metodologi Penelitian Survai. LP3ES. Jakarta.

Spillane, J. 1994. Pariwisata Indonesia (Siasat Ekonomi dan Rekayasa Kebudayaan).Kanisius. Yogyakarta 
Stankovic, Ljiljana and Suzana Dukic. 2009. "Challenges of Strategic Marketing of Tourist Destination under the Crisis Conditions". Journal of Economics and OrganizationVol. 6, No 1, 2009, pp. $23-31$.

Sugiyono. 2009. Statistik Untuk Penelitian. CV Alfabeta. Bandung

Suki, Mohd. Norazah (2012) "Examining Hotel Service Quality Elements Effects on Overall Tourists Satisfaction” European Journal of Social Sciences Vol.30 No.4 (2012), pp. 646653.

Tjiptono, Fandy. 2004. Manajemen Jasa. CV Andy Offset. Yogyakarta

Yeung, Iris M. H., and Stephen C. H. Leung. 2010. "Relationships among Service Quality, Value, Customer Satisfaction and Loyalty in a Hong Kong Harbour Cruise Company" Management Sciences Journal Vol. 1 No. 1, 2010, pp: 1-14.

Yoon Y, Uysal M (2005) An examination of the effects of motivation and satisfaction on destination loyalty: a structural model. Tour Manage 26(1):45-56. 